\title{
Análise do nível de desenvolvimento da linguagem em crianças abrigadas
}

\section{Analysis of the level of language development in sheltered children}

\author{
Juliana das Neves Nóbrega ${ }^{[a]}$, Carla Alexandra da Silva Moita Minervino ${ }^{[b]}$
}

[a] Mestranda em Psicologia Cognitiva pela Universidade Federal de Pernambuco (UFPE), Recife, PE - Brasil, e-mail: july_nobrega@hotmail.com

[b] Professora Pós-Doutora do Departamento de Educação da Universidade Federal da Paraíba (UFPB), João Pessoa, PB - Brasil, e-mail: carlamoita@globo.com

\section{Resumo}

A linguagem é uma das principais formas do ser humano estabelecer relações no mundo, ela se configura como uma função cortico-cerebral que é desenvolvida com as influências do meio ambiente e os estímulos fornecidos. A aquisição da linguagem ocorre por etapas que vão sendo atingidas à medida que a criança cresce. Conforme a literatura atual, as crianças que têm um ambiente facilitador, contato com a família e com pessoas que conversam e estimulam suas capacidades, possuem mais probabilidade de desenvolver facilmente a linguagem. No contexto das crianças abrigadas o ambiente apresenta-se não favorecedor, sem estímulos, sendo o contato das crianças com outros contextos praticamente nulo. Este estudo teve como objetivo analisar o desenvolvimento da linguagem em crianças abrigadas, para tanto foram observadas 32 crianças de creches e abrigos. Para a análise foi utilizada a escala de características para aquisição da linguagem, que visa a identificar se as características linguísticas apresentadas pelas crianças condizem com o esperado para sua idade. Os resultados observados apontam poucas habilidades linguísticas em bebês abrigados ao comparar com as habilidades dos que passam o dia na creche.

Palavras-chave: Linguagem. Aquisição. Crianças abrigadas.

\section{Abstract}

This study aimed to examine the language development in sheltered children. The language appears as the main form for human beings to establish relations in the world, it is configured as a cortical-brain function that is 
developed with environment influences and provided incentives. The language acquisition occurs in stages that are being affected as the child grows, the children who have a facilitating environment, contact with the family and talk to people and stimulate their abilities is more likely to develop language more easily. In the sheltered children context, the environment presents itself not favoring without stimuli and the children contact with other contexts is virtually nil. In research participated and 32 children, the scale of features for language acquisition in order to identify the characteristics presented by the language children are consistent with the expected results for its age. The observed results indicate few language skills in housed infants when compared with the abilities of babies who spend their days in daycare.

Keywords: Language. Acquisition. Stimuli.

\section{Introdução}

Durante o desenvolvimento a criança adquire habilidades de se relacionar e se comunicar com o mundo que vão se aprimorando com o passar do tempo, sendo uma dessas habilidades a comunicação - processo de transmissão ou informação de algo ou alguma coisa. A principal forma de comunicação do ser humano é a linguagem.

O processo de aquisição e desenvolvimento da linguagem foi explicado por diferentes autores com ideias e pontos de vista que originaram diversas teorias, dentre elas estão quatro teorias gerais. A primeira a ser destacada neste trabalho é a Teoria da Aprendizagem de Base Empirista, a qual defende que a criança desenvolve seu mundo ou conhecimento linguístico por meio de estímulo-resposta $(E-R)$, imitação e reforço.

Na segunda, a Teoria Inatista, Elliot (1981 citado por Mussen, Canger, Kangar e Huston, 1995) afirma que o cérebro está "pronto" para a aquisição da linguagem entre os 18 meses e a puberdade. $\mathrm{O}$ autor acredita que há um período sensível para esse processo de aquisição e dentro desse período espera-se que a aquisição da linguagem ocorra normalmente, mas fora dele a obtenção é difícil se não impossível.

Já na Teoria Cognitiva, o desenvolvimento da linguagem depende de certas predisposições cognitivas motivacionais, como também do processamento de informações que são inatas. $\mathrm{O}$ maior defensor dessa teoria é Jean Piaget, para quem o elemento especificamente humano é a capacidade cognitiva geral, da qual a linguagem é a expressão (Villa, 1995).

No que remete à Teoria de Interação Social, seus defensores afirmam que os fatores biológicos influenciam o processo de aquisição da linguagem, mas insistem que a interação entre as crianças e os adultos é absolutamente necessária para o desenvolvimento das habilidades linguísticas (Mussen et al., 1995). Inter-relacionar a assertiva de Mussen com o contexto de abrigo é considerar variáveis que podem predizer o adequado desenvolvimento linguístico, a saber: tempo de relação com a família; perda de entes queridos em fase de aquisição de linguagem; estímulos recebidos antes da entrada no abrigo; entre outras variáveis de caráter emocional que podem estar presentes antes da entrada no abrigo e, portanto, devem ser consideradas ao analisar-se o desenvolvimento da linguagem da criança abrigada.

As etapas de aquisição são bem desenvolvidas quando as crianças encontram ambiente propiciador e apoio familiar para apresentarem desenvolvimento saudável, tanto em aspectos físicos e motores como linguísticos. Desde o nascimento, a família é o principal núcleo de socialização da criança. Dada a sua situação de vulnerabilidade e imaturidade, seus primeiros anos de vida são marcados pela dependência do ambiente e daqueles que dela cuidam. A relação com seus pais, ou substitutos na ausência dos pais, é fundamental para sua constituição como sujeito, seu desenvolvimento afetivo e suas aquisições próprias dessa faixa etária (Plano Nacional de Promoção, Proteção e Defesa do Direito da Criança e Adolescente à Convivência Familiar e Comunitária, 2006).

Ainda de acordo coma Teoria Interacionista, as informações fornecidas pelos adultos no decorrer de sua interação com a criança ressaltam a participação do adulto no desenvolvimento linguístico da criança. A figura materna exerce uma influência particularmente privilegiada no desenvolvimento da 
linguagem, representando, para a criança, as primeiras fontes de cuidado e atenção (Ely \& Gleason, 1996 citado por Borges \& Salomão, 2003).

O desenvolvimento da linguagem segue uma sequência mais ou menos constante e depende, em parte, da programação genética, mas também de ouvir a fala das outras pessoas, o que significa estímulo ambiental. Considerando esses pressupostos este estudo se baseia na Teoria Interacionista para analisar o nível de desenvolvimento da linguagem em crianças que vivem em abrigos.

Segundo Tinoco (2001), crianças que vivem em ambientes com privações e abandono incorporam uma experiência traumática que precisa de uma rede de sustentação que possa trazer-lhes de volta a sensação de controle e estabilidade perdida, para que possam enfrentá-la.

\section{As instituiçóes de abrigo e de creche}

A instituição de abrigo consiste em um ambiente ecológico de extrema importância para crianças e adolescentes institucionalizados, configurando um tipo de microssistema. Segundo Bronfenbrenner ([1979] 1996), o microssistema é definido como um padrão de atividades, relações interpessoais e papéis experienciados pela pessoa em desenvolvimento nos ambientes que ela frequenta $\mathrm{e}$ estabelece relações face a face. Partilhando a mesma ideia, Siqueira e Dell'Aglio (2006) afirmam que é no microssistema que as crianças e os adolescentes realizam um grande número de atividades e interações, como também um ambiente com potencial para seu desenvolvimento.

O abrigo é antes de tudo um momento crucial na vida de uma criança ou um adolescente. Seu universo familiar (conhecido) é substituído pela instituição que a acolhe. Seus laços de parentesco, amizade e vizinhança ficam suspensos e ameaçados. A identidade vive uma ameaça extrema, pois na definição de quem somos importa, sobretudo, nossa filiação e a comunidade onde nascemos. A instituição supracitada é quase um não lugar, por isso deve ser transitório. Além de ter o espaço no mundo alterado, a criança e o adolescente passam pela vivência de não poder definir o futuro. Não se sabe para onde irão, nem com quem nem em qual condição (Neves, Machado \& Silva, 2007).
Para Silva e Aquino (2005), o relacionamento de crianças e adolescentes abrigados com outras famílias é uma forma de garantir o direito à convivência familiar para os meninos e as meninas cujas chances de retorno para suas famílias de origem foram esgotadas. Dessa forma, a colocação em família substituta configura-se como opção importante diante da tradicional prática brasileira de institucionalização prolongada de crianças e adolescentes em situação de risco, condenados a viver grande parte de suas vidas privados de qualquer vivência familiar.

As sequelas de um período de institucionalização prolongado em crianças e adolescentes serão maiores de acordo com a idade da criança no momento em que for afastada da família; conforme o tempo em que estas forem privadas do convívio familiar; e o tempo de espera, que interfere não só na adaptação em caso de retorno à família de origem, mas também nos casos de inserção definitiva em outra família.

No que remete à creche, esta é considerada um espaço crescente entre as formas de cuidado da criança de 0 a 6 anos e passou a ser uma opção viável para as famílias, com repercussões para a promoção da igualdade entre gêneros, na medida em que facilita o engajamento da mulher no mercado de trabalho (Lordelo, 2002).

As creches brasileiras, que atendem a população de baixo nível socioeconômico, se caracterizam por apresentar aspectos típicos como: ingresso mais precoce da criança na creche; permanência durante todo o dia; grande número de crianças por instituição; tamanho dos grupos grandes; e maior rigidez na organização das rotinas de cuidados e atividades.

Segundo Lordelo (2002), no geral, os efeitos da experiência de creche indicam várias consequências no desenvolvimento da criança, dependendo de certos fatores ligados às características da criança, de sua família e da creche.

Estudos apontam que, em relação às habilidades cognitivas, encontram-se efeitos benéficos para crianças de famílias muito pobres, desde que a creche tenha nível mínimo de qualidade (Scarr \& Eisenberg, 1993).

Nesse sentido, o presente estudo teve como objetivo analisar o nível de desenvolvimento da linguagem em crianças abrigadas, comparando-as com as crianças da creche da cidade de João Pessoa, PB. 


\section{Método}

Participantes - participaram 32 crianças compreendidas na faixa etária de 0 a 4 anos. A amostra foi dividida em dois grupos pareados de acordo com a idade: grupo 1 (grupo de controle) - composto por 16 crianças de creche; e grupo 2 (grupo experimental) - composto por 16 crianças em situação de abrigo. Os grupos 1 e 2 foram divididos em quatro subgrupos, de acordo com a faixa etária, para facilitar a aplicação do instrumento: no primeiro subgrupo, participaram crianças com a faixa etária de 0 a 1 ano; no segundo subgrupo, inserem-se as de faixa etária de 1 a 2 anos de idade; no terceiro subgrupo, crianças de 2 a 3 anos; e no quarto e último subgrupo, crianças de 3 a 4 anos de idade.

As crianças do abrigo foram para a instituição por encontrar-se em situação de maus-tratos ou por serem abandonadas pelos pais. Na instituição, os bebês permaneciam todo o dia no berçário com as cuidadoras. As crianças maiores frenquentavam aulas dadas no próprio abrigo no período da manhã e a tarde brincavam livremente no pátio. As crianças da creche viviam com seus pais e a creche destinava-se à população de nível socioeconômico baixo.

Instrumentos - foi utilizada a escala de características para aquisição da linguagem. A escala foi elaborada pelas pesquisadoras, com base nos estudos de Pedroso e Rotta (2006), objetivando identificar se as características linguísticas apresentadas pelas crianças condizem com o esperado para sua idade, sendo composta por oito itens, nos quais se agrupam características como: balbucios, gritos, primeiras palavras reais, frases de duas e três palavras, uso de artigos, pronomes.
Procedimentos - a pesquisa nas instituições de abrigo foi uma solicitação do juiz da $1^{a}$ Vara da Infância e Juventude da Comarca de João Pessoa (capital), com o intuito de avaliar o desenvolvimento linguístico das crianças abrigadas.

A coleta de dados foi realizada com o grupo 1 na instituição de abrigo e o grupo 2 na creche. Nas duas instituições, inicialmente, entrou-se em contato com os diretores, momento no qual foi apresentado o projeto de pesquisa e seus objetivos. Em seguida foram realizadas visitas semanais, nas quais as crianças foram observadas em suas atividades diárias. Dessa forma, houve a interação com as crianças e abriu-se espaço para a aplicação do instrumento, a aplicação individual, entretanto alguns itens foram avaliados no momento em que as crianças estavam em grupo, pois se fez necessária a observação da comunicação entre elas próprias e com os cuidadores.

A pesquisa foi iniciada seguindo rigorosamente as Diretrizes e Normas Regulamentadoras de Pesquisas Envolvendo Seres Humanos do Conselho Nacional de Saúde (Resolução CNS 196/96). Aos participantes foi garantido o anonimato, o sigilo de informações e a opção de se recusar a participar da pesquisa ou desistir dela sem risco de penalização. Os objetivos da pesquisa foram explicados aos participantes e, apenas após a aceitação, foi iniciada a aplicação dos instrumentos.

\section{Resultados e discussão}

Os resultados das análises passam a ser apresentados, cumprindo os objetivos propostos na presente investigação.

Tabela 1 - Itens observados entre 0 e 48 meses de idade: média, desvio-padrão, erro-padrão da média, teste U de Mann-Whitney e significância

(Continua)

\begin{tabular}{lcccccc}
\hline \multicolumn{1}{c}{ Item observado } & Instituição & Média & Desvio-padrão & $\begin{array}{c}\text { Erro-padrão } \\
\text { da média }\end{array}$ & $\begin{array}{c}\text { Teste U de } \\
\text { Mann-Whitney }\end{array}$ & Sig. \\
\hline Produção de sons & Abrigo & 3,19 & 1,276 & 0,319 & 115,5 & 0,565 \\
(primeiros 3 meses) & Creche & 3,69 & 0,479 & 0,120 & & 0,048 \\
Discriminação de sons & Abrigo & 2,38 & 0,885 & 0,221 & 81 & 0,108 \\
da fala & Creche & 2,81 & 0,544 & 0,136 & 0 & \\
Compreensão de & Abrigo & 2,44 & 0,892 & 0,223 & & 0,001 \\
palavras & Creche & 2,81 & 0,403 & 0,101 & 46 & \\
(entre 4 e 6 meses) & Abrigo & 1,63 & 1,204 & 0,301 & & \\
Produção de vogais & Creche & 2,75 & 0,447 & 0,112 & & \\
\hline
\end{tabular}


Tabela 1 - Itens observados entre 0 e 48 meses de idade: média, desvio-padrão, erro-padrão da média, teste U de Mann-Whitney e significância

\begin{tabular}{|c|c|c|c|c|c|c|}
\hline Item observado & Instituição & Média & Desvio-padrão & $\begin{array}{c}\text { Erro-padrão } \\
\text { da média }\end{array}$ & $\begin{array}{c}\text { Teste U de } \\
\text { Mann-Whitney }\end{array}$ & Sig. \\
\hline \multirow{2}{*}{ Produção de consoantes } & Abrigo & 1,25 & 1,342 & 0,335 & \multirow{2}{*}{52} & \multirow{2}{*}{0,003} \\
\hline & Creche & 2,44 & 0,629 & 0,157 & & \\
\hline \multirow{2}{*}{ Expressões faciais } & Abrigo & 2,31 & 0,704 & 0,176 & \multirow{2}{*}{59,5} & \multirow{2}{*}{0,004} \\
\hline & Creche & 2,88 & 0,500 & 0,125 & & \\
\hline \multirow{2}{*}{$\begin{array}{l}\text { Balbucio reduplicado } \\
\text { (entre } 7 \text { e } 9 \text { meses) }\end{array}$} & Abrigo & 1,56 & 1,861 & 0,465 & \multirow{2}{*}{97} & \multirow{2}{*}{0,230} \\
\hline & Creche & 1,88 & 0,806 & 0,202 & & \\
\hline \multirow{2}{*}{ Gestos comunicativos } & Abrigo & 2,63 & 1,088 & 0,272 & \multirow{2}{*}{106} & \multirow{2}{*}{0,375} \\
\hline & Creche & 2,88 & 0,619 & 0,155 & & \\
\hline \multirow{2}{*}{$\begin{array}{l}\text { Primeiras palavras reais } \\
\text { (entre } 10 \text { e } 12 \text { meses) }\end{array}$} & Abrigo & 2,63 & 1,258 & 0,315 & \multirow{2}{*}{126} & \multirow{2}{*}{0,937} \\
\hline & Creche & 2,75 & 0,775 & 0,194 & & \\
\hline \multirow{2}{*}{$\begin{array}{l}\text { Jargão (balbucio com } \\
\text { fala) }\end{array}$} & Abrigo & 1,25 & 1,915 & 0,479 & \multirow{2}{*}{75} & \multirow{2}{*}{0,039} \\
\hline & Creche & 2,13 & 0,957 & 0,239 & & \\
\hline \multirow{2}{*}{$\begin{array}{l}\text { Produção de } 10 \text { a } 50 \\
\text { palavras } \\
\text { (entre } 12 \text { e } 18 \text { meses) }\end{array}$} & Abrigo & 2,19 & 1,559 & 0,390 & \multirow{2}{*}{83,5} & \multirow{2}{*}{0,081} \\
\hline & Creche & 3,19 & 0,655 & 0,164 & & \\
\hline \multirow{2}{*}{ Frases de duas palavras } & Abrigo & 2,13 & 1,668 & 0,417 & \multirow{2}{*}{90} & \multirow{2}{*}{0,136} \\
\hline & Creche & 3,06 & 0,854 & 0,213 & & \\
\hline \multirow{2}{*}{$\begin{array}{l}\text { Chama a atenção para } \\
\text { receber resposta verbal } \\
\text { do adulto }\end{array}$} & Abrigo & 2,63 & 1,204 & 0,301 & \multirow{2}{*}{80} & \multirow{2}{*}{0,055} \\
\hline & Creche & 3,38 & 0,500 & 0,125 & & \\
\hline \multirow{2}{*}{$\begin{array}{l}\text { Produção de } 150 \text { a } 200 \\
\text { palavras } \\
\text { ( } 2 \text { anos) }\end{array}$} & Abrigo & 2,63 & 1,708 & 0,427 & \multirow{2}{*}{125} & \multirow{2}{*}{0,904} \\
\hline & Creche & 2,69 & 1,195 & 0,299 & & \\
\hline Frases de duas a três & Abrigo & 3,13 & 1,204 & 0,301 & 108 & 0415 \\
\hline palavras & Creche & 2,94 & 0,929 & 0,232 & & 0,415 \\
\hline Nomeia objetos quando & Abrigo & 3,38 & 0,806 & 0,202 & 1155 & 0605 \\
\hline inquirida & Creche & 3,31 & 0,602 & 0,151 & & \\
\hline $\begin{array}{l}\text { Usa sentenças } \\
\text { gramaticais: }\end{array}$ & Abrigo & 3,13 & 1,302 & 0,336 & & \\
\hline $\begin{array}{l}\text { preposição, artigos, } \\
\text { plural ( } 3 \text { anos) }\end{array}$ & Creche & 3,38 & 0,885 & 0,221 & 114 & 0,780 \\
\hline Formula questões & Abrigo & 3,27 & 1,100 & 0,284 & 114 & 0780 \\
\hline & Creche & 3,50 & 0,730 & 0,183 & 114 & \\
\hline Sintaxe clara (4 anos) & Abrigo & 3,69 & 0,873 & 0,218 & 127 & 0.948 \\
\hline Sintaxe clara (4 anos) & Creche & 3,75 & 0,683 & 0,171 & 121 & 0,948 \\
\hline
\end{tabular}

Considerando os dados da Tabela 1, os bebês abrigados, com idade variando entre 0 e 3 meses, revelam nos itens observados:

1) produção de sons;

2) compreensão de palavras;

3) discriminação dos sons das falas - era comum encontrar bebês que não possuíam essas habilidades. Os resultados obtidos apontaram que as crianças de creche apresentam melhores níveis nesses itens em relação às crianças de abrigo. 
Conforme Freude Burlingham (1958 citado por Barros \& Fiamenghi, 2007), crianças abrigadas podem apresentar um atraso de 6 meses na linguagem e tal fato pode ser atribuído à falta de contato com a mãe, na medida em que o aprendizado da língua está diretamente ligado à observação do comportamento e da fisionomia da mãe enquanto fala. Esse fato foi ratificado nos itens produção de vogais (4); produção de consoantes (5) e expressões faciais (6), nos quais os bebês abrigados compreendidos na faixa etária de 4 a 6 meses apresentaram diferença estatisticamente significativas para os três itens: item $4(p=0,001)$, item $5(\mathrm{p}=0,003)$ e item $6(\mathrm{p}=0,004)$, quando comparados aos dados observados para o grupo de crianças da creche.

Segundo Mussen et al. (1995), os bebês, em geral com 3 meses de idade, sorriem quando um adulto olha para baixo e conversa com eles; com 4 meses apresentam expressões de surpresa e tristeza; e expressões de raiva e medo surgem entre os 5 e 7 meses. Assim como as vocalizações, os bebês imitam as expressões que lhe são apresentadas no ambiente em que vivem, por meio do contato com as expressões dos adultos.

Nos quesitos balbucios reduplicados (7) e gestos comunicativos (8), os quais devem emergir entre 7 e 9 meses de idade, os dois grupos observados apresentaram significância equivalente para idades $(\mathrm{p}=0,230$ para o item 7 e $\mathrm{p}=0,375$ para o item 8). Conforme Newcombe (1999), o balbucio inicia-se a partir dos 6 meses de idade e por volta de 1 ano as crianças começam a dizer suas primeiras palavras com significado, como objetos do cotidiano, brinquedos, roupas, partes do corpo, nomes de pessoas próximas, palavras que comunicam o que querem: descer, subir, não e mais. Tal afirmativa corrobora os dados observados nas crianças com idade entre $10 \mathrm{e}$ 12 meses, pois nos dois grupos as primeiras palavras reais condizem com o período do primeiro ano de vida, apresentando médias $(\mathrm{p}=0,937)$ para o item primeiras palavras reais (9).

No que se refere ao item produção de jargão (10), o grupo de crianças abrigadas apresentou-se estatisticamente atrasado $(p=0,039)$ em relação às crianças observadas na creche. Para Ferreira, Silva, Silva, Merighi, Miranda, De-Vitto et al. (2008), na fase pré-linguística - que persiste até os 10 a 12 meses -, a criança inicia o balbucio, imita sons, produz jargão e compreende ordens simples com o auxílio de gestos e palavras familiares associadas a ordens simples; e na fase linguística, que ocorre por volta dos 18 meses, a criança começa a combinar duas palavras e poderá ter de 30 a 40 elementos em seu vocabulário; ela, também, conhece algumas partes do corpo; encontra objetos a pedido de alguém e apresenta brincadeira simbólica com objetos. A criança deve apresentar as funções instrumental, regulatória, interacional e pessoal.

Referente à fase linguística, os dados observados são equivalentes ao esperado $(p=0,081)$ no item 11 e $(p=0,136)$ no item 12 . As observações realizadas reforçam a ideia defendida por Flavell, Miller e Miller (1999) de que os bebês descobrem que as pessoas, e não os objetos, respondem aos seus sinais e pedidos: eles aprendem que uma bola independente dele gritar, sorrir ou chorar para ela não vai rolar até ele, entretanto, uma pessoa tende a atender seus pedidos de ajuda para atingir seus objetivos, e essa afirmação vai ao encontro das médias $(\mathrm{p}=0,055)$ encontradas no item 13.

Para Goldfeld (2002), a criança começa a desenvolver sua própria fala a partir da fala do adulto e este, além de estimular a comunicação da criança, estimula seu desenvolvimento intelectual. A estimulação da comunicação da criança, o contato com a diversidade, faz com que ela amplie seu vocabulário e, por volta dos dois anos de idade, apresente - como mostra o item 14 - produção de 150 a 200 palavras. Tanto o grupo de crianças abrigadas como o grupo de crianças da creche apresentou o esperado para sua faixa etária $(\mathrm{p}=0,904)$.

Para Costa (1999), as crianças crescem em um rico ambiente sonoro onde se sobressai e predomina a linguagem que futuramente adquirirão. $\mathrm{O}$ seu pequeno universo inclui uma série de interações com o ambiente, pais, irmãos e parentes, configurando bem ali à sua frente um legítimo caleidoscópio de sons, simbolismos e imagens. Durante essas interações, elas percebem eidentificam sequências específicas de sons que remetem consistentemente a uma lista de objetos ou ações correspondentes. Com o aumento do seu universo, a criança que já adquiriu a produção de palavras passa a uni-las em duas ou três, formando frases (item 15). As crianças observadas no abrigo e na creche apresentaram desenvolvimento adequado nessa faixa etária $(p=0,415)$, como também no item 16 , que indica a nomeação de objetos quando a criança for indagada $(\mathrm{p}=0,605)$. 
Nas crianças com idade intervalar de 3 a 4 anos, ao comparar as observações aos itens: 17 - usa sentenças gramaticais: preposição, artigos, plural; 18 - formula questões; e 19 - sintaxe clara, os resultados foram estatisticamente adequados, apresentando $\mathrm{p}=0,780$ para o item $17 ; \mathrm{p}=0,780$ para o item 18 e $\mathrm{p}=0,948$ para o item 19. Como se pode verificar com os dados observados, a forma como a criança interage com o meio social e a qualidade das informações que recebe são fatores importantes para o domínio da linguagem. Segundo Alexandre e Vieira (2004), uma criança que cresce em situação irregular poderá não ter sua base de segurança, o que pode prejudicar as relações com os outros e, principalmente, ter prejuízo nas funções de seu desenvolvimento.

A criança que vive em ambiente saudável e estimulador tende a apresentar desenvolvimento satisfatório, tanto nos aspectos linguísticos como motores e físicos. O papel do adulto-cuidador é primordial nesse desenvolvimento, como afirma Scarr e Eisenberg (1993). As crianças que têm cuidadores mais responsivos e de maior envolvimento apresentam comportamentos mais exploratórios e mais positivos, além de apresentarem melhor relacionamento entre pares.

Nos estudos de Alexandre e Vieira (2004) com crianças institucionalizadas foram observados cuidadores que permeiam o autoritarismo, o medo e o abandono. Nesse caso, os bebês apresentaram falta de estimulação, as crianças foram agressivas e tiveram atraso na linguagem. O cuidador é o mediador de muitos comportamentos que a criança desenvolverá, regulando sua atenção, curiosidade, cognição, linguagens, emoções entre outros. Quando a criança é privada dessa relação, ela desenvolve angústia, exagerada necessidade de amor, forte sentimento de vingança e, em consequência, culpa e depressão (Barros \& Fiamenghi, 2007).

As boas condições ambientais e de relação entre as crianças e os outros são fatores de desenvolvimento. Nesse sentido, Mayor (1989 citado por Pérez, 1992) afirma que o domínio pleno da linguagem constitui um objetivo inalcançável, enquanto qualquer habilidade e nível de uso podem melhorar por parte dos mesmos sujeitos quando se dão as condições apropriadas, ou por parte de outros sujeitos em função de certas condições específicas.

\section{Consideraçóes finais}

No momento em que procuramos analisar a linguagem e seu nível de desenvolvimento em crianças abrigadas, comparando-as com as da creche, não pretendemos apontar as crianças abrigadas como atrasadas ou incapazes, e sim procuramos atentar para os níveis de desenvolvimento linguístico em que elas se encontram, tendo em vista que não vivem em ambientes considerados normais, ou seja, vivem com sua família e têm contato social frequente, favorecendo seu desenvolvimento, pois vivem privadas do contato familiar e contato social externo, permanecendo em companhia apenas dos cuidadores e profissionais da instituição.

Considerando os dados apresentados, este estudo concluiu que as crianças abrigadas possuem atrasos em relação à linguagem quando comparadas a crianças de creches. As causas para esse atraso, neste estudo, não são claramente identificáveis. Nesse aspecto, é importante ressaltar o papel exercido pelos cuidadores como figuras de referência na educação dessas crianças, participando como "mãe" ou "pai" e como educador. As crianças abrigadas têm o seu mundo resumido ao contexto do abrigo e os cuidadores tornam-se responsáveis por todo o aparato de conhecimentos sociais, culturais e educacionais necessários ao desenvolvimento dessas crianças.

\section{Referências}

Alexandre, D. T., \& Vieira, M. L. (2004). Relação de apego entre crianças institucionalizadas que vivem em situação de abrigo. Psicologia em Estudo, 9(2), 207-217.

Barros, R. C. de, \& Fiamenghi Jr, G. A. (2007). Interações afetivas de crianças abrigadas: um estudo etnográfico. Ciência \& Saúde Coletiva, 12(5), 1267-1276.

Borges, L., \& Salomão, N. (2003). Aquisição da linguagem: Considerações da perspectiva da interação social. Psicologia: Reflexão e Crítica, 2(16), 327-336.

Brasília. (2006). Plano Nacional de Promoção, Proteção e Defesa do Direito de Crianças e Adolescentes à Convivência Familiar e Comunitária/Secretaria Especial dos Direitos Humanos. Brasília, DF: Conanda. 
Bronfenbrenner, U. (1996). A ecologia do desenvolvimento humano: experimentos naturais e planejados. (M. A. Verríssimo, Trad.) Porto Alegre: Artes Médicas. (Trabalho original publicado em 1979).

Costa, S. S. (1999). Audição, comunicação e linguagem: Um convite à reflexão. Revista HCPA, 19(2), 147-166.

Ferreira, A. T., Silva, M. M. A., Silva, L., Merighi, L. B. M., Miranda, A. M., De-Vitto, L. P. M. et al. (2008). Desempenho comunicativo em trigêmeos prematuros. Revista CEFAC, 10(1), 15-21.

Flavell, J. H., Miller, S. A., \& Miller, P. H. (1999). Cognição social. In J. H. Flavell, S. A. Miller \& P. H. Miller. Desenvolvimento cognitivo (pp.146-185). Porto Alegre: Artmed.

Goldfeld, M. (2002). Aquisição da linguagem e desenvolvimento cognitivo. In M. Goldfeld. A criança surda: Linguagem e cognição numa perspectiva sócio-interacionista (pp. 58-62), São Paulo: Plexus.

Lordelo, E. R. da. (2002). Agora vá com a tia que a mamãe vem mais tarde: Creche como contexto brasileiro de desenvolvimento. In E. R. da. Lordelo, A. M. A. Carvalho, \& S. H. Koller (Org.). Infância brasileira e contextos de desenvolvimento (pp. 75-96). São Paulo: Casa do Psicólogo; Salvador, BA: Ed. daUFBA.

Mussen, P. H., Canger, J. J., Kangar, J., \& Huston, A. C. (1995). Período da meninice: Linguagem e desenvolvimento cognitivo. In P. H. Mussen. Desenvolvimento da personalidade da criança (pp. 212-230). São Paulo: Havana.

Neves, M. E. R., Machado, M. A. S., \& Silva, T. V. da. (2007). O perfil das crianças e dos adolescentes abrigados em João Pessoa. In B. L. F. Almeida, M. E. R. Neves \& S. M. A. Xavier. Realidade dos abrigos para crianças e adolescentes de João Pessoa/ PB: Desafios e Perspectivas (pp. 148-175). João Pessoa: Ed. da UFPB.

Newcombe, N. (1999). Linguagem e comunicação. In N. Newcombe. Desenvolvimento infantil: Abordagem de Mussen. Porto Alegre: Artmed.

Pérez, M. J. P. (1992). Lenguaje infantil: Análisis de tres procedimientos expresivos. Didáctica (Lengua y Literatura), 4, 157-206.
Pedroso, F. S., \& Rotta, N. T. (2006). Transtornos na linguagem. In L. Ohlweiller \& R. S. Riesgo. Transtornos da aprendizagem: Abordagem neurológica e multidisciplinar (pp. 131-150). Porto Alegre: Artmed.

Scarr, S., \& Eisenberg, M. (1993). Child care research: Issues, perspectives, and results. Annual Review of Psychology, 44, 613-644.

Siqueira, A. C., \& Dell'Aglio, D. D. (2006). O impacto da institucionalização na infância e na adolescência: Uma revisão de literatura. Psicologia \& Sociedade, 18(1), 71-80.

Silva, E. R. A., \& Aquino, L. M. C. (2005). Os abrigos para crianças e adolescentes e o direito à convivência familiar e comunitária. Brasília: IPEA.

Tinoco, V. (2001). O luto de crianças institucionalizadas em casas de abrigo. In L. Mazorra \& V. Tinoco (Org.). Luto na infância: Intervenção psicológica em diferentes contextos (pp. 146-169). São Paulo: Livro Pleno.

Villa, I. (1995). Aquisição da linguagem. In C. Coll \& A. Marchesi. Desenvolvimento psicológico e educação (pp. 69-80). Rio Grande do Sul: Artes Médicas.

Recebido: 21/02/2010

Received: 02/21/2010

Aprovado: $31 / 08 / 2010$

Approved: 08/31/2010 